\title{
The longstanding, persistent confusion surrounding surgery for atrial fibrillation
}

\author{
James L. Cox, MD
}

\begin{abstract}
The surgical treatment of atrial fibrillation $(\mathrm{AF})$ persists in being a confusing topic, despite the fact that surgeons have been able to treat this entity successfully for more than 2 decades. Much of the confusion stems from electrophysiologic concepts that have arisen from observations made after catheter ablation, where the interventional electrophysiologists do not know the precise location, length, depth, or width of their lesions. In addition, the lack of a physiologically based classification system that is meaningful for patients undergoing interventional therapy for $\mathrm{AF}$, the indiscriminant use of unproven lesion patterns, the inability to create transmural and contiguous ablative lesions reliably, the lack of agreement regarding what constitutes a surgical failure, and the lack of a standard means of assessing postoperative results have all contributed to the current state of confusion.
\end{abstract}

\section{CONCOMITANT SURGERY FOR AF}

Some surgeons are now questioning the validity of treating AF surgically in the case of patients who are already entering the operating room for other cardiac surgery, such as mitral valve repair. Gammie and associates ${ }^{1}$ recently reviewed the Society of Thoracic Surgeons National Cardiac Database and reported that of 67,389 patients with $\mathrm{AF}$ who underwent surgery for other cardiac problems only $38 \%$ underwent a concomitant surgical procedure for $\mathrm{AF}$, including $52 \%$ of those undergoing mitral valve surgery, $28 \%$ of those undergoing aortic valve surgery, and $24 \%$ of those undergoing isolated coronary artery bypass grafting (CABG). This disappointing performance was seen despite the publication of multiple studies from around the world confirming the ability of a variety of concomitant surgical procedures to eliminate $\mathrm{AF}^{2-7}$ Most authorities believe that concomitant AF surgery is indicated not only for patients with $\mathrm{AF}$ who are undergoing mitral valve surgery ${ }^{8-10}$ but also for patients with $\mathrm{AF}$ who are undergoing $\mathrm{CABG}$ or aortic valve surgery. ${ }^{11}$ Ridding the patient of $\mathrm{AF}$ at the time of mitral valve, aortic valve, or coronary artery surgery has been documented to cause no increased surgical risk ${ }^{12}$ yet results in multiple benefits relative to leaving these patients in AF postoperatively. The benefits include not only a better quality of life ${ }^{13}$ but also less postoperative

From the Emeritus Evarts A. Graham Professor of Surgery, Division of Cardiothoracic Surgery, Washington University School of Medicine, St. Louis, Mo.

Address for reprints: Mary Kay Keers, 3905 Annapolis Lane, Suite 105, Minneapolis, MN 55447 (E-mail: jamescoxmd@aol.com).

J Thorac Cardiovasc Surg 2010;139:1374-86

0022-5223/\$36.00

Copyright (c) 2010 by The American Association for Thoracic Surgery doi: 10.1016/j.jtcvs.2010.02.027 morbidity ${ }^{14}$ lower incidences of thromboembolic events and valve-related complications, ${ }^{15,16}$ improvement in the commonly associated problem of tricuspid regurgitation, ${ }^{17,18}$ and improved patient survival. ${ }^{16,19}$ Indeed, the surgical literature of the past decade leaves no doubt that the concomitant surgical treatment of AF associated with other cardiac surgery should increase in the future.

The current lack of aggressiveness in treating AF with concomitant surgical procedures has other consequences. For example, it is uncommon for surgeons to perform stand-alone operations for AF. The usual explanation for this is, "My referring cardiologist won't refer these patients." There are likely several reasons for the lack of referrals, but 2 stand out: (1) stand-alone surgical procedures are not referred because many surgeons do not even routinely treat AF with a concomitant cardiac surgical procedure, and (2) most contemporary surgical techniques are left-sided procedures, and although they may be fairly effective as concomitant procedures for AF, they are not nearly so effective when applied as stand-alone procedures for AF. Indeed, the stand-alone surgical results with left-sided procedures may be no better than those attained by catheter ablation. Because these procedures are obviously more invasive, why should cardiologists be expected to refer their patients with AF to surgeons if they cannot expect to see a significant improvement in outcome?

\section{PAROXYSMAL AND CHRONIC AF}

The term atrial fibrillation is a clinical diagnosis that is based on the findings of an irregular $\mathrm{P}$ wave and an irregularly irregular QRS complex on the standard limb-lead electrocardiogram. The clinical diagnosis of AF reveals little, however, about the underlying electrophysiologic events that are actually occurring in the atria. For example, the electrocardiographic findings of AF can be caused by a single unstable macro-reentrant circuit in either atrium, by 2 simultaneous macro-reentrant circuits in a single atrium, by a single macro-reentrant circuit in each atrium, or by as many as 6 simultaneous macro-reentrant circuits (Figure 1). ${ }^{20-23} \mathrm{AF}$ is either paroxysmal or nonparoxysmal. Individual episodes of paroxysmal AF (PAF) depend on focal atrial triggers for their induction; once induced, however, the individual episodes are sustained by self-perpetuating macro-reentrant circuits in the atrium until they spontaneously terminate. Haïssaguerre and associates ${ }^{24}$ and others ${ }^{25}$ have demonstrated that the focal triggers that induce PAF are in and around the pulmonary vein (PV) orifices in approximately $90 \%$ of patients. 


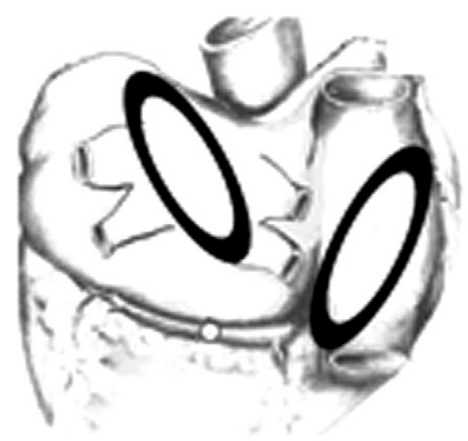

A

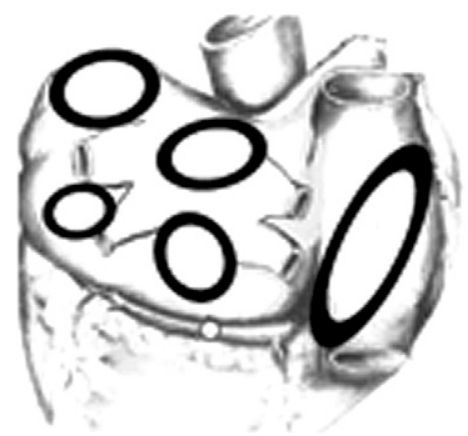

C

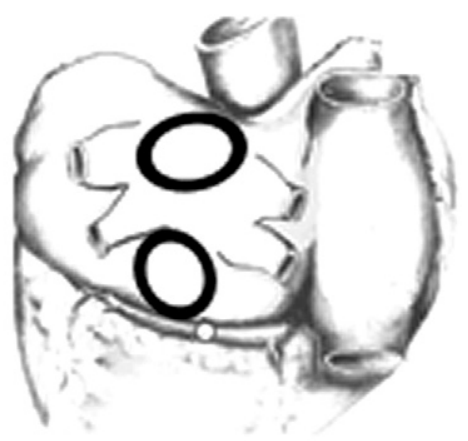

B

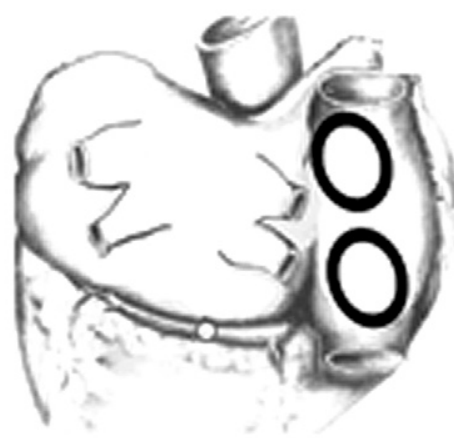

D

FIGURE 1. Atrial fibrillation. This posterior view of the heart is also shown in Figures 4, 5, 6, 8, and 9. These are some of the combinations of macroreentrant circuits in the atria that can cause the electrocardiographic findings of atrial fibrillation. Note that in most cases the macro-reentrant circuits are smaller in the left atrium than in the right atrium (B, C). Also, most "normal" right atria are capable of harboring only 1 much larger macro-reentrant circuit, the so-called "flutter wave," which traverses the cavotricuspid isthmus (A, C). In patients with primary atrial fibrillation, however, which arises de novo in a grossly normal heart, there may be 2 or more macro-reentrant circuits in the right atrium (D).

By definition, all AF that does not occur sporadically is nonparoxysmal AF, which includes the subcategories of persistent, longstanding persistent, permanent, chronic, continuous, or any other arbitrary designation that refers to $\mathrm{AF}$ that is not paroxysmal (Figure 2). Because the term nonparoxysmal $A F$ is cumbersome and unfamiliar to most surgeons, however, the remainder of this discussion will refer to all nonparoxysmal $\mathrm{AF}$ as chronic $A F(\mathrm{CAF})$.

Whereas PAF depends on atrial triggers for its induction, $\mathrm{CAF}$ requires no such triggers because it does not need to be repeatedly induced. CAF occurs because the selfperpetuating macro-reentrant circuits (drivers) in the atria that spontaneously terminate in patients with PAF no longer terminate; thus, the AF becomes nonparoxysmal or chronic. These macro-reentrant drivers can occur virtually anywhere in either atrium and are usually at least $5 \mathrm{~cm}$ in diameter, not 1 to $2 \mathrm{~cm}$ in diameter or smaller as implied in such prominent publications as the Heart Rhythm Society/European Heart Rhythm Association/European Cardiac Arrhythmia Society Expert Consensus Statement. ${ }^{26}$ The presence of these selfperpetuating macro-reentrant drivers, and the fact that they are physically large rather than focal, is the reason that PV isolation alone will not cure CAF and why it is necessary to add strategically placed linear lesions in these patients.

\section{PRIMARY AND SECONDARY AF}

Arrhythmia surgeons deal almost exclusively with $\mathrm{AF}$ that arises secondary to some type of left heart problem, usually mitral valve disease but also aortic valve disease, ischemic heart disease, or left heart failure. This AF is frequently referred to as concomitant $A F$, but it is more accurate to think of it as secondary AF that is treated with a concomitant surgical procedure. A few arrhythmia surgeons also treat patients with $\mathrm{AF}$ that is not associated with another cardiac problem severe enough to warrant surgery. This is commonly referred to as stand-alone $A F$, but it is more accurate to think of it as primary AF that is treated with a stand-alone surgical procedure. Before performing concomitant surgery for $\mathrm{AF}$, all patients should be classified as having either secondary PAF or secondary CAF (Figure 3). Before performing stand-alone surgery for $\mathrm{AF}$, all patients should be classified as having either primary PAF or primary CAF. 


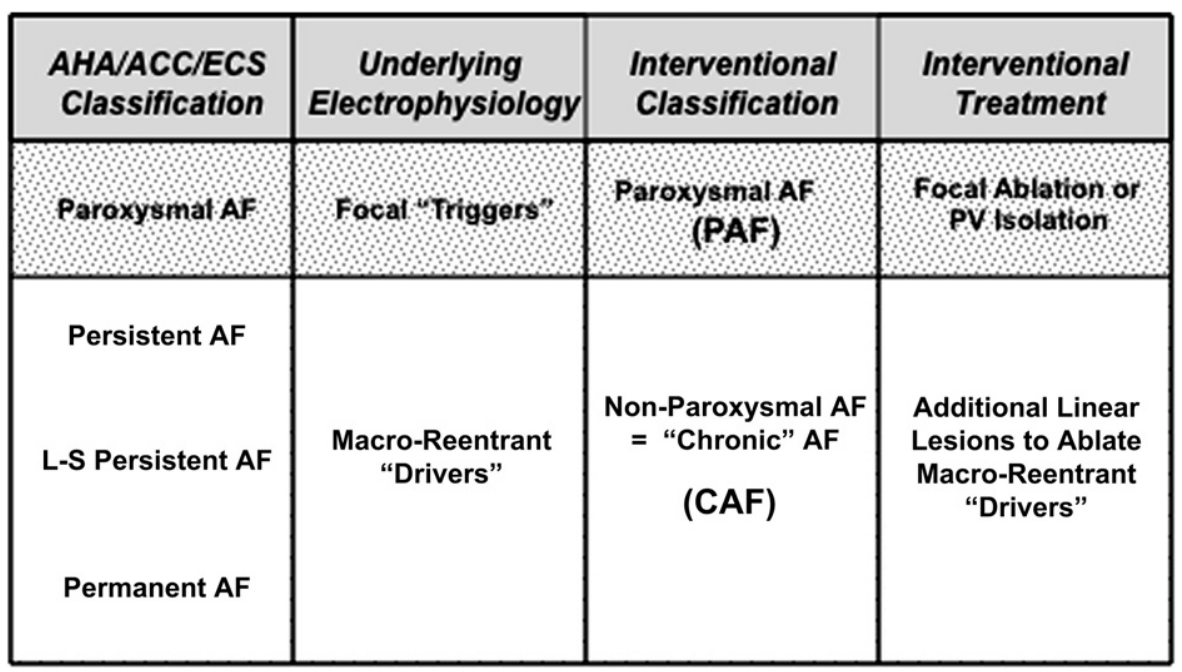

FIGURE 2. The American Heart Association/American College of Cardiology/European Cardiology Society classification system is extremely helpful to physicians who treat atrial fibrillation with drugs. It is of little or no value to interventional cardiologists or surgeons who treat atrial fibrillation by interventional methods, however, because it is not based on any underlying electrophysiologic differences between various arbitrary categories, nor does it help in determining appropriate interventional procedure to be performed. There are only 2 underlying electrophysiologic mechanisms in atrial fibrillation that can be altered physically by catheter or surgical intervention: focal triggers that induce individual episodes of atrial fibrillation and macro-reentrant drivers that sustain atrial fibrillation once it has been induced. Interventional classification in this figure is based on these 2 electrophysiologic properties of atrial fibrillation that not only differentiate paroxysmal atrial fibrillation from nonparoxysmal atrial fibrillation but also dictate appropriate interventional approach to each. Because nonparoxysmal atrial fibrillation is cumbersome and unfamiliar to most interventionalists and surgeons, it has been largely replaced in literature with more traditional and familiar chronic atrial fibrillation. When applied as a descriptor of atrial fibrillation, chronic does not indicate duration of atrial fibrillation but rather its persistence and thus includes all forms of atrial fibrillation that are not paroxysmal. Thus for purposes of interventional therapy, not only is it more convenient to think of all atrial fibrillation as being either paroxysmal or chronic but it is also more accurate from both mechanistic and therapeutic standpoints. AHA, American Heart Association; $A C C$, American College of Cardiology; ECS, European Cardiology Society; $A F$, atrial fibrillation.

\section{Primary and Secondary PAF}

Both primary and secondary PAF are caused by focal triggers that are usually located in or near the PV orifices, and both therefore can be treated successfully with PV isolation. Surgeons are rarely referred patients with primary PAF, because satisfactory results can be attained by catheter ablation in these cases. Because secondary PAF occurs frequently in patients undergoing other cardiac surgery, however, concomitant surgical PV isolation is a commonly used procedure. ${ }^{27}$ Although this would seem to be appropriate for all patients with secondary PAF, PV isolation alone can be quite arrhythmogenic, especially in patients with enlarged or diseased left atria, in which setting atypical left atrial flutter (Figure 4) is a frequent postoperative occurrence. Atypical left atrial flutter is characterized by a long reentrant circuit formed around the PV-isolating lesions in which the electrical impulse travels along the left atrial isthmus between the inferior PVs and the mitral annulus, through the atrial septum, around the anterior left atrium above the mitral annulus, and then in the lateral left atrium beneath the orifice of the left atrial appendage. If a patient is undergoing surgery for mitral valve disease in which the left atrium is already opened it is therefore advisable, even for secondary PAF, to go ahead with a complete left atrial maze III lesion pattern, which usually adds less than 15 min- utes to the operative procedure. The right atrial maze III lesions can then be added during the rewarming phase without extending the operative time. In patients with secondary PAF who are undergoing aortic valve surgery or CABG, however, where a left atriotomy is not otherwise required, it is reasonable to perform a simple epicardial PV isolation.

\section{Primary and Secondary CAF}

Although both primary and secondary CAF depend on the presence of macro-reentrant drivers for their maintenance, there are critical electrophysiologic differences between the two that can doom a surgeon's stand-alone practice for $\mathrm{AF}$ if they are ignored. The critical difference relates to the number of macro-reentrant circuits that can occur in the right atrium under various clinical conditions. These differences explain why satisfactory results can often be attained in patients undergoing concomitant surgery ${ }^{28,29}$ but not standalone surgery, despite identical lesion pattern and energy source. ${ }^{30}$ The durations of the local refractory periods in atrial tissue determine the physical size of local macroreentrant circuits. ${ }^{31}$ Areas of the atrium with shorter refractory periods can harbor smaller macro-reentrant circuits, whereas areas with longer refractory periods can harbor only larger macro-reentrant circuits. The refractory periods in the left atrium are normally shorter than those in the right 


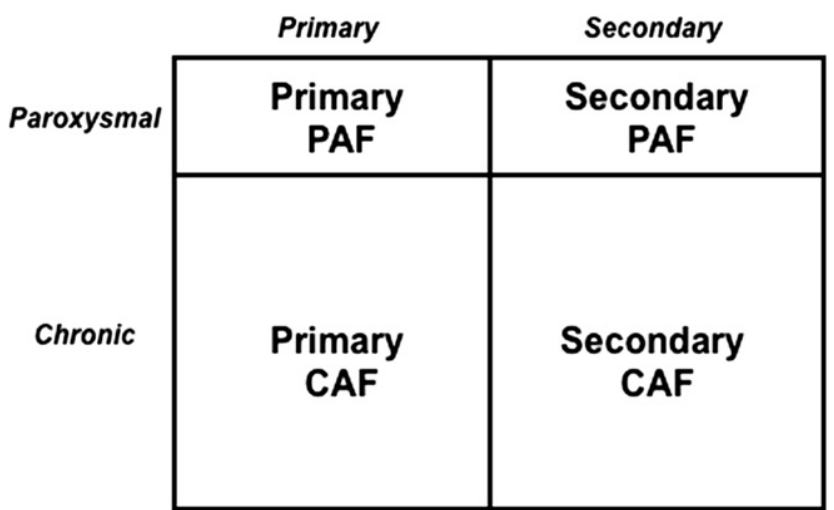

FIGURE 3. According to the interventional classification described in Figure 2, all patients with atrial fibrillation have either paroxysmal atrial fibrillation or chronic atrial fibrillation. In addition, all patients with atrial fibrillation can be divided into those with primary and secondary atrial fibrillation. Primary atrial fibrillation is defined as atrial fibrillation that occurs in patients who have no associated gross cardiac diseases or abnormalities that are severe enough to warrant surgical correction. Thus, any surgical procedure for primary atrial fibrillation would be performed as a stand-alone procedure; that is, the patient is having cardiac surgery solely to treat atrial fibrillation. Secondary atrial fibrillation is defined as atrial fibrillation resulting from other cardiac diseases or abnormalities that are severe enough to warrant cardiac surgery. Thus, any surgical procedure for secondary atrial fibrillation would be added to the main surgical procedure as an adjunctive or concomitant procedure for atrial fibrillation. All patients who are to undergo surgical treatment for atrial fibrillation should be categorized into 1 of these 4 distinctive groups, not only for purposes of determining optimal surgical therapy but also to report accurate and meaningful surgical results. $P A F$, Paroxysmal atrial fibrillation; $C A F$, chronic atrial fibrillation.

atrium, ${ }^{32}$ so macro-reentrant circuits that form in the left atrium are usually smaller than those in the right atrium (Figure 1,C). In fact, because of its relatively long refractory periods, the normal right atrium is capable of harboring only a single large macro-reentrant circuit, the classic atrial "flutter wave" that traverses the cavotricuspid isthmus. ${ }^{32,33}$ Thus to choose the appropriate surgical approach for each patient, one must take into account not only the type of AF present but also the clinical statuses of both the right and left atria.

Secondary CAF with a normal right atrium. Because the right atrium may not be affected by left heart problems, such as mitral or aortic valve disease, ischemic heart disease, or left heart failure, the normal right atrium in these patients is still capable of supporting only a single macro-reentrant circuit, the right atrial flutter wave (Figure 5). Thus the macro-reentrant drivers responsible for the secondary CAF in such patients reside predominantly in the left atrium, and concomitant AF surgical procedures confined to the left atrium therefore can have a relatively high success rate in such patients. After strictly left-sided concomitant procedures, however, approximately $10 \%$ of these patients will have postoperative atrial flutter originating from the right atrium. ${ }^{34}$ Some surgeons therefore add a right atrial "flutter

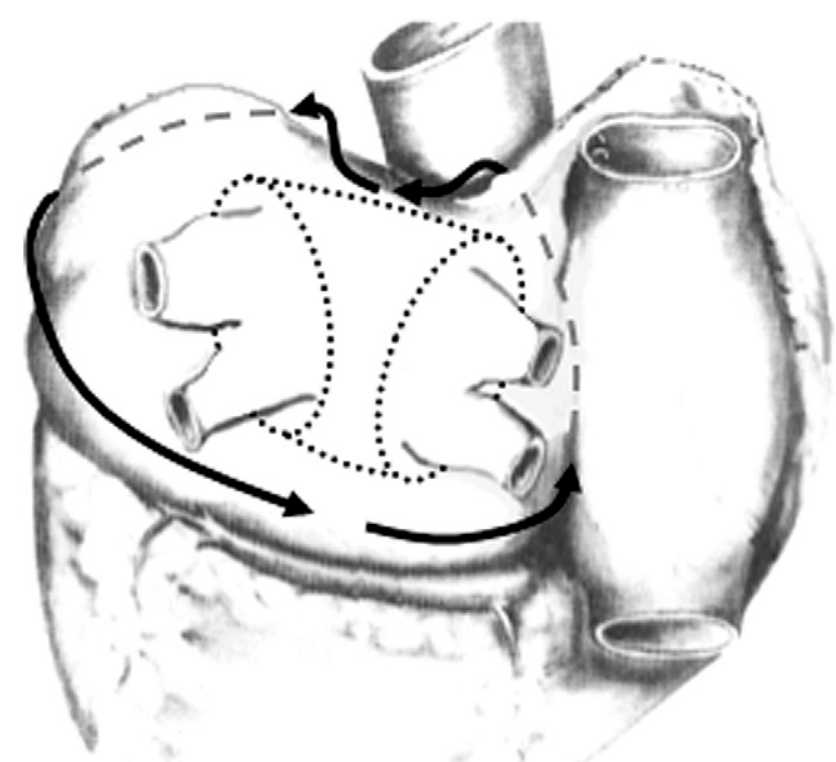

FIGURE 4. Atypical left atrial flutter. This is an iatrogenic arrhythmia that can occur after pulmonary vein isolation by any of the techniques usually used, regardless of the energy source used. The electrical impulse travels around the reentrant circuit diagrammed approximately 240 times per minute. After being blocked 2:1 in the atrioventricular node, atypical left atrial flutter causes a regular ventricular response of approximately 120 beats/min and is a particularly stable and recalcitrant arrhythmia.

lesion" to their concomitant left-sided surgical procedures. Others choose to ignore the possibility of postoperative atrial flutter from the right atrium and let their cardiologists treat it with catheter ablation should it occur. Either approach is reasonable.

Secondary CAF with an abnormal right atrium. If the right atrium is enlarged or stretched as a result of the left heart problem, it may become large enough to support two simultaneous macro-reentrant circuits (Figure 6). In that case, concomitant AF procedures confined to the left atrium will fail because the postoperative persistence of multiple macro-reentrant circuits in the enlarged right atrium can still cause AF postoperatively. Thus although concomitant leftsided AF procedures are generally fairly effective for secondary CAF, if there is any hint of right atrial involvement, the patient should have the full set of maze III lesions applied in the right atrium as well as in the left atrium. This is perhaps the most frequent reason for recurrent $\mathrm{AF}$ after strictly left-sided concomitant $\mathrm{AF}$ procedures for the treatment of CAF secondary to mitral valve disease. Moreover, the addition of a right atrial flutter lesion would have no effect whatsoever on the occurrence of postoperative $\mathrm{AF}$ in these patients, because that lesion is only effective for atrial flutter coming from the right atrium.

Because it is not always possible to know whether the right atrium is affected by the left heart problems in these patients, even when looking directly at the right atrium during 


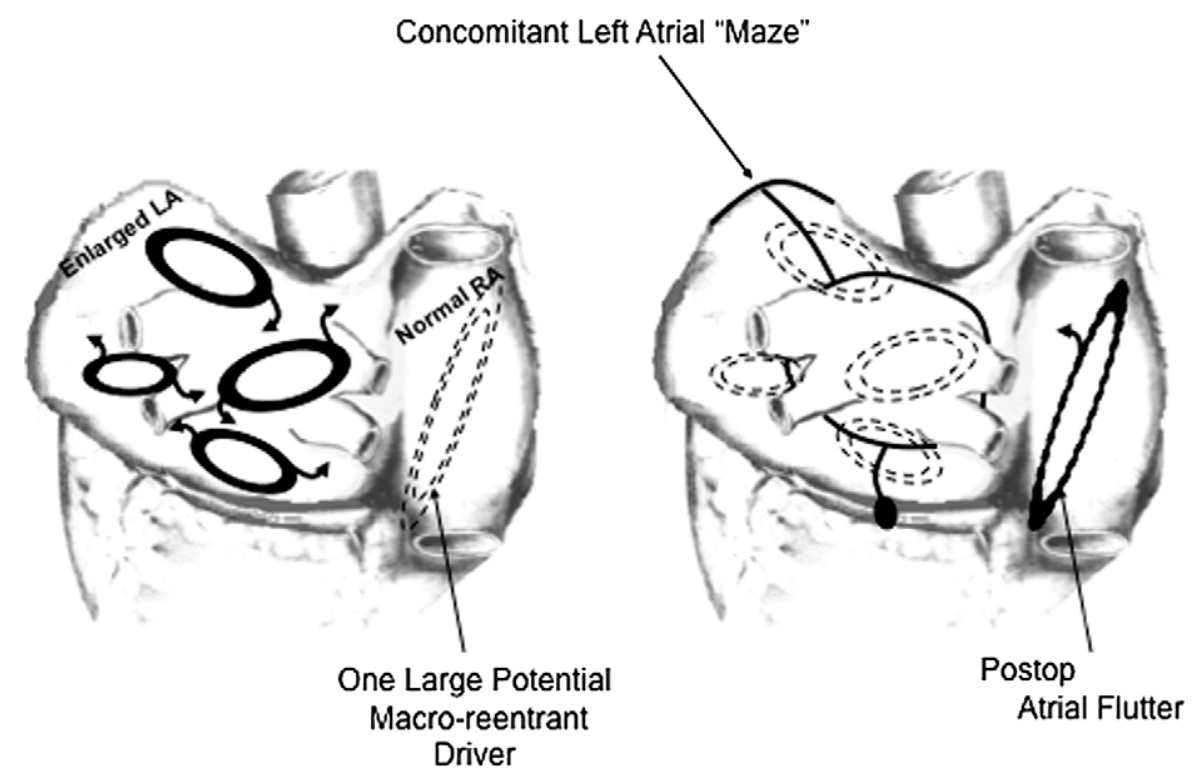

FIGURE 5. Concomitant left-sided surgery for secondary chronic atrial fibrillation with an enlarged left atrium (LA) and a normal right atrium $(R A)$. Left panel, Patients with chronic atrial fibrillation secondary to mitral valve disease usually have an enlarged left atrium, but the right atrium may be normal. In such cases, macro-reentrant drivers responsible for the chronic atrial fibrillation are invariably located in the left atrium, explaining why concomitant surgical procedures confined to the left atrium are quite successful in this group of patients. Because the right atrium is normal, it can harbor only 1 large macro-reentrant circuit, the so-called "flutter wave," which usually traverses the cavotricuspid isthmus. Right panel, If concomitant surgical procedure is confined to the left atrium and the right atrium is ignored, classic atrial flutter from persistent right atrial flutter wave will occur postoperatively in about $10 \%$ of patients. A right atrial "flutter lesion" placed across the cavotricuspid isthmus at surgery will preclude this postoperative atrial flutter but it requires opening the right atrium. Thus, most surgeons ignore the right atrium entirely and have their electrophysiologist treat any postoperative right atrial flutter by catheter ablation.

surgery, and because it takes only about 10 minutes and no additional pump time to perform the right atrial lesions of the maze III lesion set, it seems prudent to add the right-sided lesions in all patients undergoing combined mitral valve and AF surgery. This is especially true in view of the fact that, unlike the right atrial flutter lesion, the right atrial maze III lesions prevent both AF and atrial flutter that might arise postoperatively in the right atrium. If the associated surgical procedure is aortic valve replacement or CABG, the best results for secondary CAF would be attained by performing a full biatrial maze III lesion pattern. Because that set currently requires a left atriotomy for proper performance, however, the decision of whether to add the biatrial procedure or perform some other lesser procedure is at the surgeon's discretion.

A word of caution is warranted here. The right atrial cavotricuspid flutter lesion ablates right atrial flutter but not right $\mathrm{AF}$, whereas the right atrial maze lesions ablate both. It is never acceptable, however, to perform both the right atrial cavotricuspid flutter lesion and the right atrial maze lesions in the same patient. This combination of lesions actually isolates the lower third of the right atrial free wall (Figure 7), and that is the site of origin of the normal sinus rhythm impulse during heart rates less than 60 beats/ min. ${ }^{35}$ Thus if the heart rate normally drops below that level, say when a patient is asleep, there may be no primary mech- anism for generating a sinus rhythm if the lower third of the right atrium has inadvertently been isolated.

Primary CAF. I was wrong for several years in believing that a properly performed stand-alone left atrial maze III lesion set without the right atrial maze III lesions would cure primary $\mathrm{CAF}$ at the same rate that it cured secondary $\mathrm{CAF}$ when performed as a concomitant procedure. ${ }^{28,36,37}$ Clinical experience eventually demonstrated that after a stand-alone left-sided procedure for primary CAF, the recurrence rate of AF could be $50 \%$ or more. ${ }^{30}$ Clearly, AF surgical procedures that are confined to the left atrium fail much more often when they are used as stand-alone procedures to treat primary CAF than when they are used as concomitant procedures to treat secondary CAF. This dramatic difference in surgical results was the observation that established unequivocally that there was a critical difference in the electrophysiologic mechanisms underlying secondary CAF and primary CAF.

It is important to recognize that primary CAF arises de novo in an otherwise grossly normal heart, or at least in a heart that has no obvious clinical cause for the $\mathrm{AF}$ (mitral, aortic, or ischemic disease). Why? One reason is that in patients with primary $\mathrm{CAF}$, the right atrium may have abnormally short refractory periods, meaning that their corresponding right atrial macro-reentrant circuits can be smaller than normal. ${ }^{38}$ Thus, 


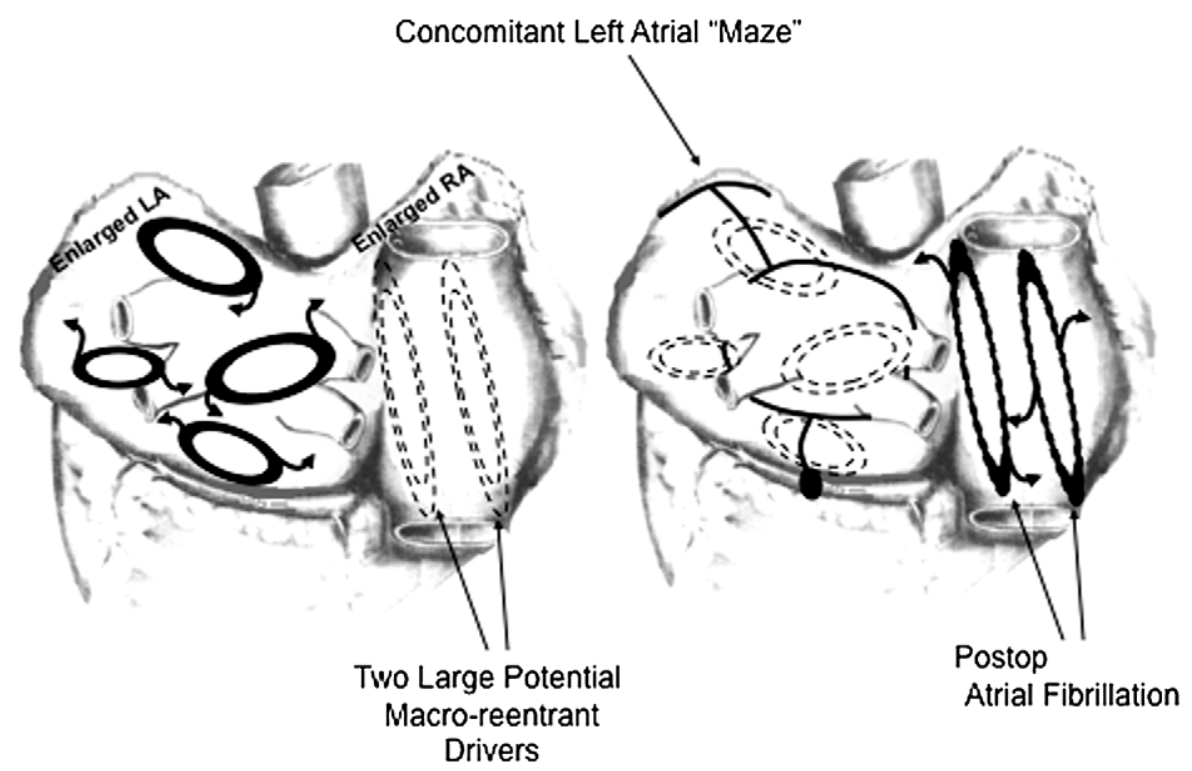

FIGURE 6. Concomitant left-sided surgery for secondary chronic atrial fibrillation in which both atria are enlarged. Left panel, In many patients with chronic atrial fibrillation secondary to mitral valve disease, the right atrium $(R A)$ may be enlarged enough to support 2 or more large macro-reentrant circuits, even though the long refractory periods are unchanged from normal. In this case, a concomitant surgical procedure confined to the left atrium (LA, right panel) may ablate the culprit macro-reentrant drivers in the left atrium but leave behind the 2 potential macro-reentrant circuits in the right atrium. Should these right atrial macro-reentrant circuits then become active, they can serve as drivers for atrial fibrillation after surgery. The addition of a right atrial "flutter lesion" will have no effect on the recurrence of postoperative atrial fibrillation in such patients. For this reason, the right atrial lesions of the maze procedure should be added in all patients with chronic atrial fibrillation that is secondary to mitral valve disease unless the surgeon can be absolutely certain that the right atrium is completely normal (see Figure 5), which is very difficult without a preoperative electrophysiologic study.

unlike the situation in the normal right atrium, multiple macro-reentrant drivers can reside simultaneously within the normal-appearing right atrium in patients with primary $\mathrm{CAF}$ (Figure 8). Clearly, a stand-alone AF surgical procedure confined to the left atrium, with or without addition of a right atrial flutter lesion, would fail in such patients because of the postoperative persistence of the multiple macro-reentrant drivers in the right atrium. Indeed, a sure way to preclude the development of a viable clinical practice treating primary $\mathrm{CAF}$ with stand-alone surgical procedures is to use procedures that are confined to the left atrium!

\section{IMPORTANCE OF LESION PATTERNS}

In 1998, Haïssaguerre and associates ${ }^{24}$ published their seminal article demonstrating for the first time that most episodes of AF are induced by focal triggers in and around the PV orifices. This article led to an explosion of industry involvement in the field, with the introduction of multiple new energy sources incorporated into surgical devices that were designed primarily for encircling the PVs. ${ }^{28,39-42}$ This simultaneous introduction of 2 variables into the surgical treatment of AF, new energy sources and new lesion patterns, directly violated a cardinal rule of scientific investigation, which demands that all variables in an experiment be controlled save the one being evaluated. The violation of this simple but basic scientific principle preordained the massive confusion that we now face in trying to interpret the reason for surgical failures. Are they due to the inadequacy of the energy source or to inappropriate lesion sets? With two variables having been introduced simultaneously some 10 to 12 years ago, it is impossible to answer that question definitively. The common practice is to incriminate the energy source rather than the lesion pattern as the cause of AF surgical failures, ${ }^{39,43,44}$ a practice that I believe is a direct result of the influence exerted by industry on the mindset of surgeons involved in treating AF. Industry is less attuned to the importance of lesion patterns than it is to the differences in energy sources because there is no profit from lesion patterns, only from energy sources. Thus incomplete lesion patterns are rarely incriminated as the reason for suboptimal surgical results.

Another reason that the importance of lesion patterns has been deemphasized is that during the past decade, the primary objective of most new surgical procedures for AF has been to make them as minimally invasive as possible. Consequently, the lesion pattern has been relegated to a secondary role in surgical procedures, being largely dictated by the limitations of surgical exposure and the previously selected energy source. ${ }^{39,43,45}$ It is now clear, however, that if the primary end point is an optimal outcome, the future design of $\mathrm{AF}$ surgical procedures must start with the premise that whatever surgical exposure or energy source is used, the lesion pattern should be consistent and involve both atria. Barnett and Ad's extensive meta-analysis of the 


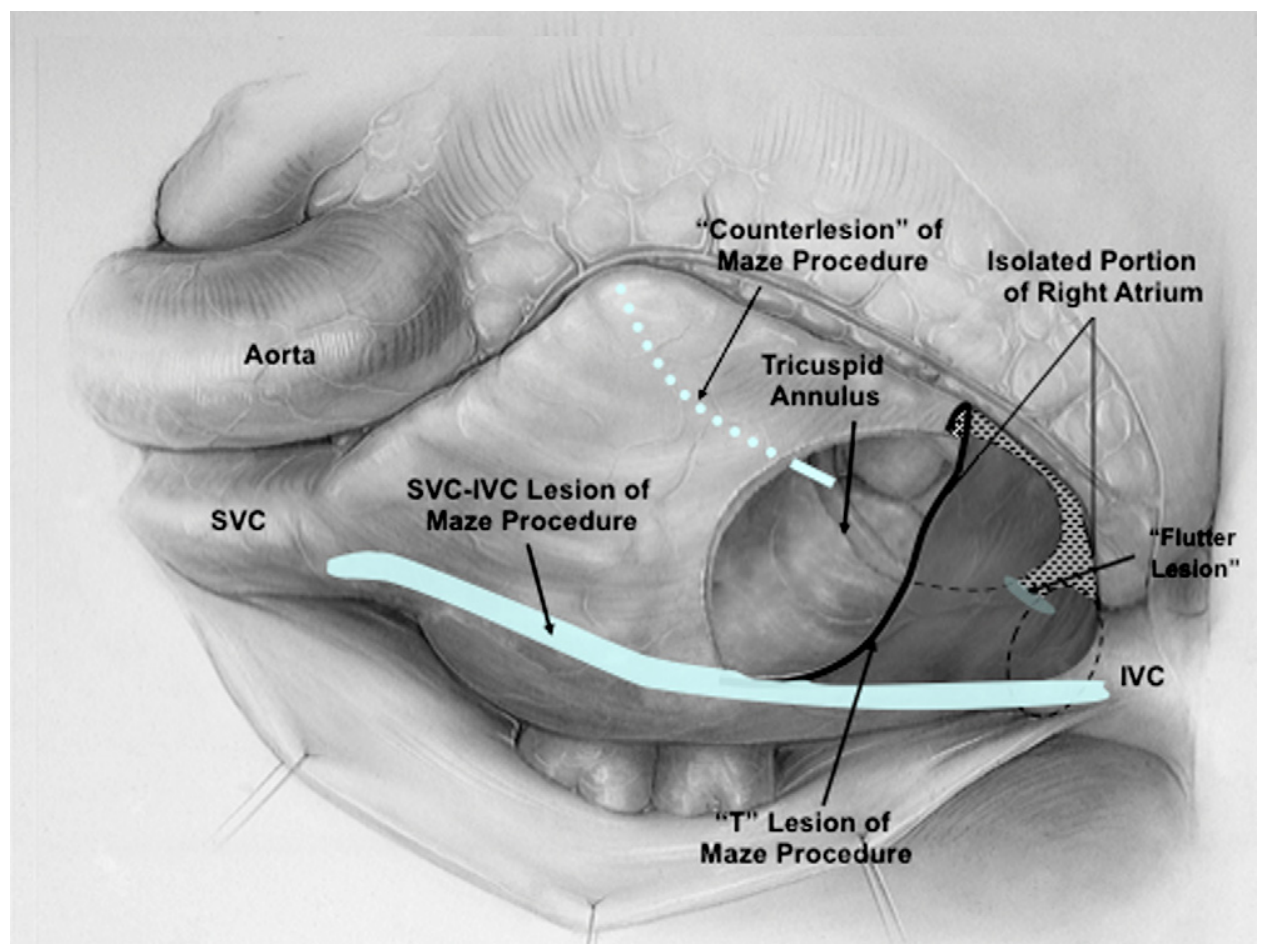

FIGURE 7. Inadvertent isolation of the lower right atrium. The combination of the superior vena cava (SVC) to inferior vena cava (IVC) lesion and the $\mathrm{T}$ lesion of the maze procedure normally results in the lower one third of the right atrium being activated via the cavotricuspid isthmus after surgery. Therefore, adding the flutter lesion across the cavotricuspid isthmus in combination with those 2 lesions of the maze procedure electrically isolates the lower one third of the atrium. Thus, the flutter lesion should never be added in combination with the right atrial maze lesions.

surgical literature covering 69 studies and 5885 surgical patients $^{46}$ and Rostock and colleagues' catheter ablation study from Hamburg ${ }^{47}$ both resulted in the same conclusion. Furthermore, after a thoughtful in-depth analysis of the logic behind different lesion patterns, Gillinov ${ }^{48}$ agreed that biatrial lesion sets were necessary for optimal surgical results and stated that the biatrial maze III lesion pattern still attained the best outcomes. If we accept that optimal surgical results depend on the creation of completely transmural and contiguous bilateral atrial lesions in the maze III pattern, surgeons can start from that established reference point and then address the issue of how to place that lesion set in or on the heart with the least possible degree of surgical invasiveness.

These studies reinforce the historical message that the cut-and-sew maze III procedure has been successful not only because all of the surgical incisions are contiguous and transmural but also because they are placed in the correct pattern. Despite complete transmurality of all of the incisions, had they been placed in some other arbitrary pattern, such as so-called "left-sided mazes" or simple PV isolation, the knife and scissors would have had just as high a failure rate as most procedures with the newer ablative energy sources. The logical corollary is that any ablative energy source that is applied in a maze III lesion pattern in which every lesion is both transmural and contiguous will cure AF at the same rate as the old cut-and-sew surgical technique. Because surgical failures are almost invariably attributed to the energy source rather than to the lesion pattern, a potentially excellent energy source could be unjustifiably discarded as ineffective simply because it was used to create the wrong lesion pattern. This may well have been the case with microwave and laser energy, both of which were withdrawn from the market despite the fact that few if any complete maze III lesion patterns were ever created with either energy source. Thus how sure can one be that the energy sources were the problem? On the contrary, if one performs a complete and accurate maze III lesion pattern using any of the available energy sources and it fails, one can be certain that either the energy source was inadequate (not all lesions were transmural), a surgical error was made in applying that energy source, or both.

Patients, industry, cardiologists, and many surgeons are accustomed to hearing such comments as, "The patient had a maze procedure for AF, but it failed." Of course this could be true, but commonly the patient in question did not undergo a true maze procedure at all, but rather one of the "modified" procedures. Some of these procedures actually have the term maze as a part of their common titles, such as the Wolf MiniMaze procedure, ${ }^{39,49}$ which is in reality only a simple PV isolation plus closure of the left atrial appendage. Although the Wolf MiniMaze is an innovative way to isolate the PVs with minimally invasive 


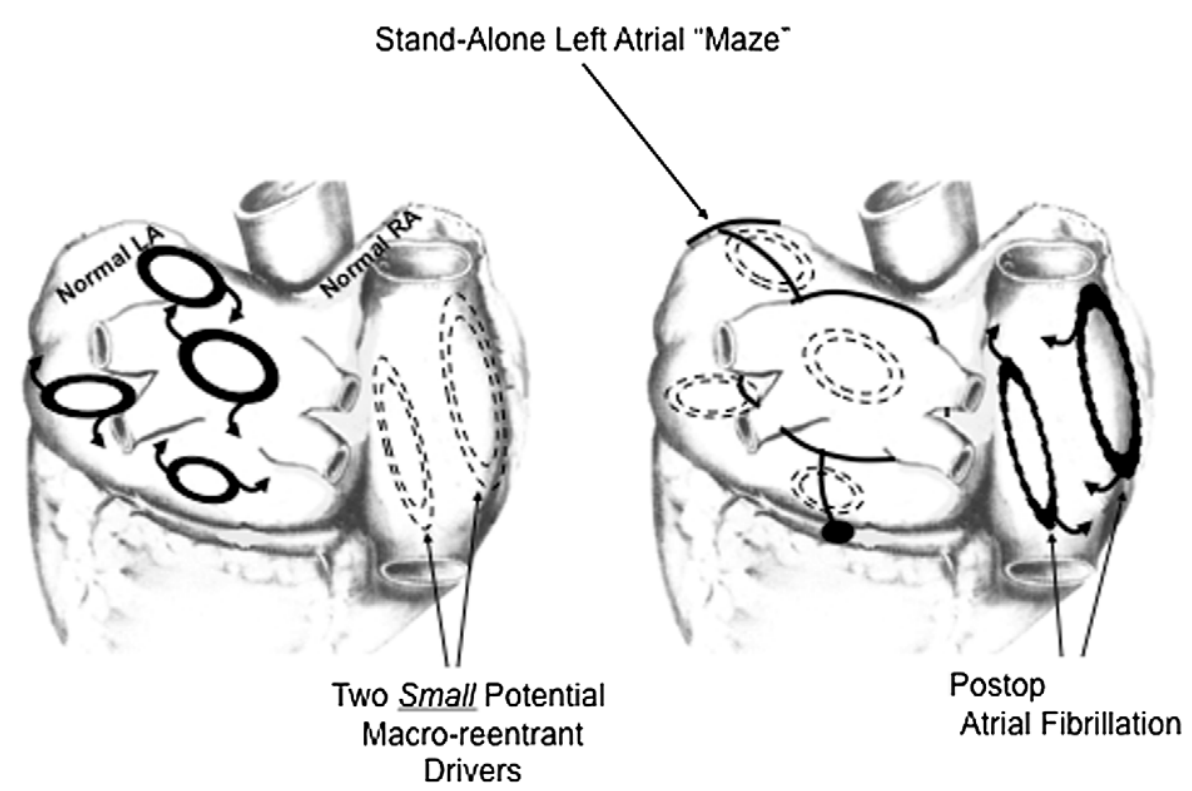

FIGURE 8. Stand-alone left-sided surgery for primary chronic atrial fibrillation with normal left atrium $(L A)$ and normal right atrium $(R A)$. The right atrium can normally support only 1 large macro-reentrant circuit because of its long refractory periods; however, in patients with primary chronic atrial fibrillation that arises de novo in a grossly normal heart, the right atrium may have shorter refractory periods and therefore can harbor smaller macro-reentrant circuits. This allows a normal-appearing right atrium to support 2 macro-reentrant circuits, which can be just as important in driving atrial fibrillation as those in the left atrium (see Figure 1,D). Thus stand-alone surgical procedures that are confined to the left atrium in patients with primary chronic atrial fibrillation often fail because these right atrial drivers persist postoperatively. Adding a right atrial "flutter lesion" has no effect whatsoever on the recurrence of postoperative atrial fibrillation in these patients. It is this unique electrophysiologic difference between right atrial electrophysiology in primary and secondary chronic atrial fibrillation that results in strictly left-sided procedures being highly successful as concomitant procedures for secondary chronic atrial fibrillation but dismal failures as stand-alone procedures for primary chronic atrial fibrillation.

surgical techniques, its electrophysiologic mechanism of action in treating $\mathrm{AF}$ is not different from any other PV isolation procedure. Thus it offers no advantage relative to catheter ablation, especially in patients with CAF.

The Ex-Maze procedure is performed with radiofrequency energy, and although the lesion pattern is closer in principle to the maze lesion set than to the Wolf MiniMaze set, the Ex-Maze still falls short of creating a true maze of lesions in the atria. Therefore the possibility of recurrent atrial macro-reentry (AF or atrial flutter) is not precluded because there is no atrial line to the mitral annulus, there is no coronary sinus lesion, and the arbitrary right atrial lesions are unproven. ${ }^{50}$ Nevertheless, the minimally invasive approach used by Kiser in performing the Ex-Maze procedure represents a significant innovation in surgical technique that may eventually prove to be useful in performing a truly endoscopic epicardial maze procedure. Kiser has now abandoned the original Ex-Maze procedure in favor of the socalled "convergent procedure," which is a hybrid operation that includes epicardial lesions placed by the surgeon and endocardial lesions placed by an interventional cardiologist (Kiser AC, unreferenced personal communication, Oct 2009).

Similarly, the recent claim that the "Dallas lesion set" is "electrophysiologically equivalent to all the left atrial lesions of the Cox maze III" is incorrect, nor is it accurate to state that "it has been proven that the right-sided lesions of the maze procedure are not necessary., 51 Theoretically, the Dallas procedure (Figure 9) should be just as effective as the maze III procedure in preventing postoperative atypical left atrial flutter (Figure 4) if the anterior lesion across the dome of the left atrium is indeed transmural and reaches the mitral annulus as claimed. It does not matter whether the reentrant circuit responsible for atypical left atrial flutter is interrupted posteriorly, as in the maze procedure, or anteriorly, as in the Dallas procedure; however, that is where most similarities between the 2 procedures end.

The anterior incision across the dome of the left atrium down to the left fibrous trigone in the Dallas procedure divides Bachmann's bundle, which is the finger-sized muscle bundle that connects the top of the right atrium to the top of the left atrium. This is the pathway that allows the left and right atria to become activated at virtually the same instant (within $40 \mathrm{~ms}$ ), even though the impulse is generated in the right atrium alone. This in turn assures that atrioventricular synchrony is maintained in both sides of the heart. A similar lesion that divided Bachmann's bundle was included in the original maze I procedure ${ }^{52}$ and it was a major reason that we modified the maze I procedure to the maze II and finally the maze III procedure. ${ }^{53,54}$ The combination of 


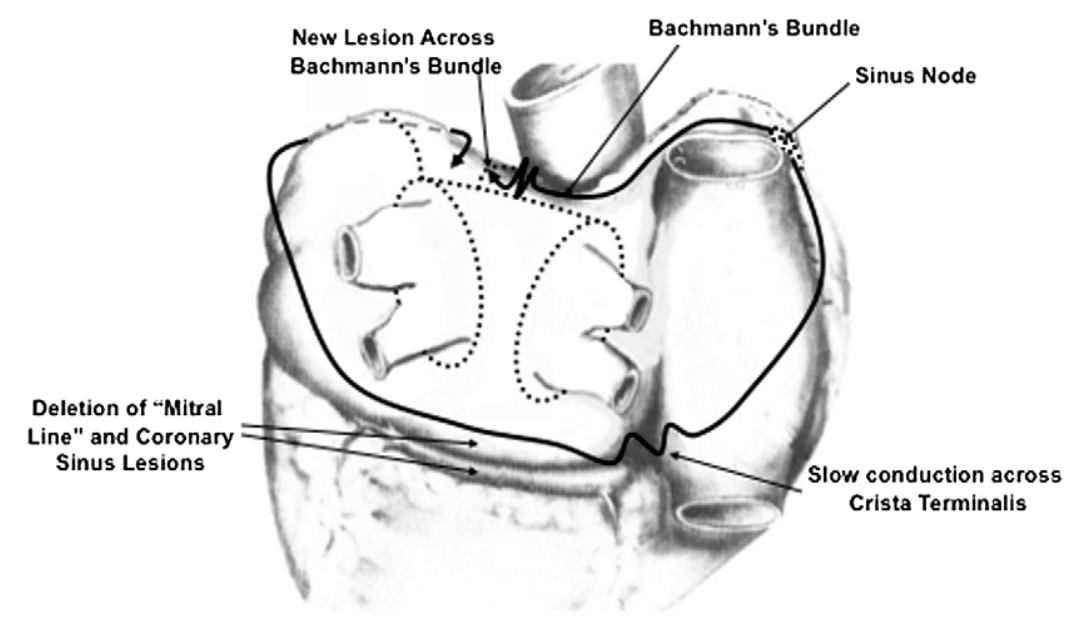

FIGURE 9. The Dallas procedure. Conduction from the sinus node in the top of the right atrium to the top of the left atrium normally takes only 40 milliseconds because of the rapidity of impulse propagation across Bachmann's bundle. This rapid impulse conduction across Bachmann's bundle is possible because its fibers are oriented parallel to the direction of impulse propagation. This allows virtually simultaneous activation and contraction of the right and left atria. In the Dallas procedure, the "mitral line" and coronary sinus lesions of the maze procedure are deleted and a new lesion is placed anteriorly across the dome of the left atrium. This lesion blocks all conduction from the right to left atrium across Bachmann's bundle and forces the right atrial sinus impulse to activate the left atrium via a posterior route across the crista terminalis and the left atrial isthmus between the inferior pulmonary veins and the posterior mitral annulus. The fibers of crista terminalis are oriented perpendicular to the direction of impulse propagation and, therefore, the speed of conduction is greatly slowed as the impulse traverses the crista terminalis. This results in a delay in the activation of the left atrium that, if severe enough, can result in the left atrium actually being activated almost simultaneously with the left ventricle. If that occurs, as it did in the original maze I procedure, all left atrial transport function is essentially lost because the left atrium will be contracting against the closed mitral valve.

dividing Bachmann's bundle and encircling the PVs with a "box lesion" can cause a severe intra-atrial conduction delay in some patients, which results in the left atrium and the left ventricle beating at the same time, effectively eliminating all left atrial transport function. In addition, the rationale behind the Dallas procedure, that it is a technically easier way to prevent postoperative atypical left atrial flutter, ignores the fact that atypical left atrial flutter is not the only failure mode in patients who have no mitral line or coronary sinus lesion placed beneath the inferior PVs. In fact, a common failure mode in such patients is late AF from the presence of macro-reentrant drivers in the left atrial isthmus near the coronary sinus (Figure 10). ${ }^{55}$ The left atrial isthmus, including the coronary sinus, has been shown repeatedly to be a very arrhythmogenic region of the atrium, ${ }^{56-61}$ and one ignores the importance of these anatomic structures in initiating and sustaining AF at one's own risk. Finally, the Dallas lesion set currently includes no right atrial lesions at all, ${ }^{51}$ a fact that will cause many unnecessary failures independent of those that will arise from deletion of the lines of conduction block across the left atrial isthmus/coronary sinus.

Having enumerated these many differences between the Dallas procedure and the maze procedure, it should be mentioned that the potential intra-atrial conduction block with the Dallas procedure may not be as severe as it was with the maze I procedure, because conduction across the left atrial isthmus was complete in the maze I procedure because of the "mitral line" and coronary sinus lesions. Deletion of those lesions in the Dallas procedure allows the impulse to travel from the right atrium to the left atrium across this isthmus. The impulse will not travel as quickly across the isthmus as it normally would across Bachmann's bundle, however, because the myocardial fibers in Bachmann's bundle are oriented parallel to (in the direction of) impulse propagation and therefore promote extremely rapid conduction. After the creation of conduction block through Bachmann's bundle with the Dallas procedure, the sinus impulse must traverse the crista terminalis posteriorly to enter the left atrium, and those fibers are oriented perpendicular to the direction of impulse conduction, which greatly slows conduction of the sinus impulse from the right atrium to the left atrium (Figure 9). ${ }^{62}$ Although this example of "anisotropy of conduction" will not likely result in complete conduction block between the right and left atria posteriorly, it may well delay conduction from the right atrium to the left atrium enough to cause the left atrium and the left ventricle to beat simultaneously as they too often did after the original maze I procedure. If this intra-atrial conduction delay proves to be insignificant, if recurrent $\mathrm{AF}$ from residual macro-reentrant drivers in the left atrial isthmus does not prove to be a problem, and if surgeons add the right-sided maze III lesions, the left atrial lesion set of the Dallas procedure holds promise as a viable alternative to the left atrial lesion set of the maze procedure. A separate critical concern with Dallas approach, however, relates to the questionable 


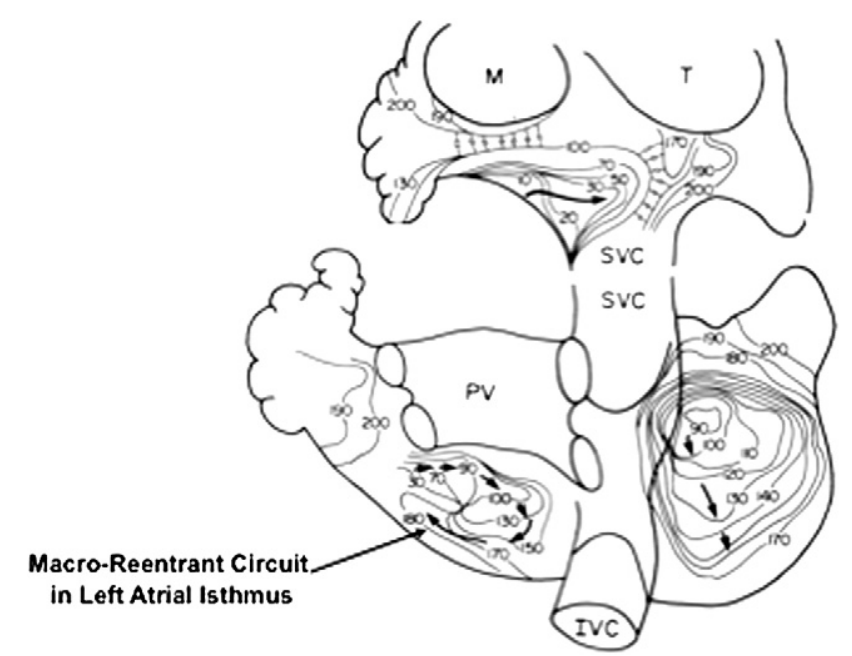

FIGURE 10. Atrial fibrillation. This is the intraoperative activation map of the first patient ever mapped with a multipoint (156 epicardial bipolar electrodes) computerized mapping system while in atrial fibrillation. Note the macro-reentrant circuit in the left atrial isthmus between the inferior pulmonary veins $(P V)$ and the mitral annulus. Because the Dallas procedure deletes the "mitral line" and coronary sinus lesions of the maze procedure, the Dallas procedure is vulnerable to such macro-reentrant drivers causing recurrent atrial fibrillation postoperatively. Indeed, occasional failure to block conduction across the left atrial isthmus was the Achilles' heel of the maze procedure, as all 7 early maze procedure failures were shown to have postoperative conduction across the left atrial isthmus. Some recurrences took the form of atypical left atrial flutter but others were due to atrial fibrillation resulting from macro-reentrant circuit in the left atrial isthmus, as shown in this figure. The Dallas procedure should theoretically be as effective in preventing atypical left atrial flutter as the maze procedure, but the Dallas procedure remains susceptible to recurrent atrial fibrillation due to the type of persistent macro-reentry in the left atrial isthmus shown in this figure. Posterior view with anterior atria "flipped up" for exposure. $M$, Mitral valve; $T$, tricuspid valve; $S V C$, superior vena cava; $I V C$, inferior vena cava.

ability of any currently available energy source to create reliable permanent transmural lesions in the atrium from the epicardial surface in a beating heart. Thus the unpredictability of an epicardial energy source coupled with a new unproven lesion pattern portends a significant failure rate in the future, again with no ability to tell whether the failures are due to the energy source or to the lesion pattern.

\section{DEFINITIONS OF SUCCESS AND FAILURE}

"Freedom from AF" is a legitimate end point only if it means the same thing to all investigators. After a blanking period of 3 to 6 months, all cases of postoperative AF, postoperative atypical left atrial flutter, and postoperative classic right atrial flutter should be classified as failures. Clinically, patients often tolerate AF better than they tolerate atrial flutter, ${ }^{63}$ so if a surgical procedure successfully ablates AF but leaves the patient with atrial flutter, the procedure cannot honestly be called a success, or at least it won't be consid- ered so by the patient! Thus if only AF is reported as a failure of a surgical procedure, the alleged success rates are not only inflated but also misleading and inaccurate.

The methods by which these postoperative recurrences are to be detected remain a source of some controversy. It has been suggested that the "harder one looks" for AF recurrences, the more recurrences one will find. For example, the apparent success rates in a given series of patients undergoing surgery for AF are best if the only end point is absence of AF on a standard electrocardiogram, slightly worse if the patients are subjected to 24-hour Holter monitoring, and worst if they are continuously monitored for 1 week. ${ }^{64,65}$ Although this may be demonstrable in some series, I believe that there are 2 reasons that such studies are not as important as they might seem. First, if one does the correct operation to begin with, the disparity between the different monitoring methods will virtually disappear, because the AF will have been successfully ablated and no amount of monitoring will change that fact. In other words, major differences among these 3 methods of follow-up occur primarily in series in which the original operation was inadequate. Second, the 1-week monitoring is usually done with a system that is incapable of differentiating between irregular premature atrial beats and runs of AF. Because we know that at least $10 \%$ of the "triggers" that induce AF lie outside the isolated PV cuff after surgery, and because no surgical procedure ablates these, we should expect roughly $10 \%$ of patients to have occasional episodes during which their nonisolated "triggers" cause premature atrial beats, events that could be erroneously interpreted by long-term monitoring to be AF. Because 24-hour Holter monitoring can distinguish between clusters of irregular premature atrial beats and AF, the apparent "incidence of AF", would naturally be lower with the Holter monitor than with the nondiscriminating long-term monitoring systems. Nevertheless, because of the popular notion that these different end points affect the surgical results, one might question the validity of the success rates reported by Prasad and colleagues ${ }^{66}$ for our original cut-and-sew maze patients from $\mathrm{St}$ Louis, the suggestion being that those results were artificially inflated because of the lack of prolonged monitoring at term. On the contrary, rather than performing such a passive assessment as "monitoring" of our original maze patients, the first 69 patients were all brought back to Barnes Hospital 6 months postoperatively for complete formal electrophysiologic studies. All patients had been off all antiarrhythmic medication for at least 3 months, and every patient was subjected to the full programmed electrical stimulation and burst pacing protocols that they had received preoperatively. AF could not be induced in a single patient. The patients were then started on a continuous intravenous isoproterenol drip, and the programmed electrical stimulation and burst pacing protocols were repeated. Again, not a single instance of AF could be induced. Importantly, there 
were no differences in the 6-month, 5-year, 8.5-year, 10year, and 15-year follow up results in the 69 patients who had complete postoperative electrophysiologic studies documenting cure of their $\mathrm{AF}$ and those who were not subjected to postoperative electrophysiologic studies. ${ }^{31,63,66,67}$

\section{FINAL COMMENTS}

At some time during the past decade, the notion evolved that a $70 \%$ to $80 \%$ success rate is satisfactory when performing surgery for AF. Who lowered the bar? We don't accept such a success rate for any other type of adult cardiac surgery, so why should we accept it for AF surgery? A recent update on 16,309 patients undergoing catheter ablation for $\mathrm{AF}$ of all types reported success rates in that same range, ${ }^{68}$ so why would a cardiologist refer a patient with AF for surgery if our results are no better than theirs? As with other types of cardiac surgery, 2 factors will determine whether AF surgery has a future: (1) outcomes and (2) invasiveness. Regardless of how "minimally invasive" we can make a procedure, however, surgery will never become a frontline option for AF unless we can cure essentially all patients with a single operation. Of course, that operation must compare favorably with catheter ablation in terms of invasiveness, but outcomes will determine our relevance in the foreseeable future.

We are not in competition with cardiologists for patients who might undergo stand-alone surgery for primary PAF or patients who need concomitant surgery for secondary PAF or CAF. Cardiologists treat primary PAF, and surgeons already treat secondary PAF and CAF. Thus the future of AF surgery depends on our ability to develop a stand-alone operative procedure that will offer patients with primary CAF a viable alternative to the cardiologists' approach. Despite their gross "rounding up" of the true success rates for catheter ablation in the update mentioned previously, ${ }^{68}$ only a few cardiologists actually attempt to treat primary CAF, because fortunately most of them are unwilling to create the massive atrial tissue destruction that is necessary to attain such outcomes in these patients. ${ }^{69-71}$ They do, however, have another option for patients with primary CAF. With the recent development of percutaneous methods for closing the left atrial appendage, ${ }^{72,73}$ cardiologists will likely begin to treat Primary CAF by electively ablating the His bundle, inserting a permanent pacemaker, and closing the left atrial appendage. Not only will this allow all antiarrhythmic drugs to be discontinued, but closure of the left atrial appendage will also allow warfarin to be stopped. ${ }^{73}$ This approach has the additional advantage of being simple enough to be performed by all interventional cardiologists, not just trained electrophysiologists, and we can certainly expect the pacemaker companies to look favorably on this practice. It is this procedure that will be our competition for patients with primary CAF in the future. We will have to develop a surgical procedure that is at least somewhat comparable in invasiveness to catheter ablation, meaning that it will have to be an endoscopic or robotic off-pump procedure that avoids general anesthesia, endotracheal intubation, and postoperative chest tubes. More importantly, it will have to achieve outcomes comparable to those of the original cutand-sew maze III procedure. That may seem like a tall order, but if it can be accomplished, we should be able to compete very effectively with a procedure that leaves patients in $\mathrm{AF}$ and requires a permanent pacemaker! If so, the 1.2 million people in the United States with primary CAF will become potential surgical patients. If not, AF surgery will continue to be confined to the relatively few patients with secondary $\mathrm{AF}$ who are already coming to our operating rooms. That sounds like a challenge worthy of a surgeon's attention.

\section{References}

1. Gammie JS, Haddad M, Milford-Beland S, Welke KF, Ferguson TB Jr, O'Brien SM, et al. Atrial fibrillation correction surgery: lessons from the Society of Thoracic Surgeons National Cardiac Database. Ann Thoracic Surg. 2008;85: 914-5.

2. Blomström-Lundqvist C, Johansson B, Berglin E, Nilsson L, Jensen SM, Thelin S, et al. A randomized double-blind study of epicardial left atrial cryoablation for permanent atrial fibrillation in patients undergoing mitral valve surgery: the SWEDish Multicentre Atrial Fibrillation study (SWEDMAF). Eur Heart J. 2007;28:2902-8.

3. Myrdko T, Sniezek-Maciejewska M, Rudziński P, Myć J, Lelakowski J, Majewski J. Efficacy of intra-operative radiofrequency ablation in patients with permanent atrial fibrillation undergoing concomitant mitral valve replacement. Kardiol Pol. 2008;66:932-40.

4. Chen MC, Chang JP, Chen YL. Surgical treatment of atrial fibrillation with concomitant mitral valve disease: an Asian review. Chang Gung Med J. 2008;31: 538-45.

5. von Oppell UO, Masani N, O'Callaghan P, Wheeler R, Dimitrakakis G, Schiffelers S. Mitral valve surgery plus concomitant atrial fibrillation ablation is superior to mitral valve surgery alone with an intensive rhythm control strategy. Eur J Cardiothorac Surg. 2009;35:641-50.

6. Chevalier P, Leizorovicz A, Maureira P, Carteaux JP, Corbineau H, Caus T, et al. Left atrial radiofrequency ablation during mitral valve surgery: a prospective randomized multicentre study (SAFIR). Arch Cardiovasc Dis. 2009;102:769-75.

7. Kim JB, Yun TJ, Chung CH, Choo SJ, Song H, Lee JW. Long-term outcome of modified maze procedure combined with mitral valve surgery: analysis of outcomes according to type of mitral valve surgery. J Thorac Cardiovasc Surg. 2010;139:111-7.

8. Alfieri O, Benussi S. Mitral valve surgery with concomitant treatment of atrial fibrillation. Cardiol Rev. 2000;8:317-21.

9. Gillinov AM. Ablation of atrial fibrillation with mitral valve surgery. Curr Opin Cardiol. 2005;20:107-14.

10. Gehi AK, Adams DH, Filsoufi F. The modern surgical management of atrial fibrillation. Mt Sinai J Med. 2006;73:751-8.

11. Geidel S, Ostermeyer J, Lass M, Geisler M, Kotetishvili N, Aslan H, et al. Permanent atrial fibrillation ablation surgery in CABG and aortic valve patients is at least as effective as in mitral valve disease. Thorac Cardiovasc Surg. 2006;54:91-5.

12. Ad N, Cox JL. The significance of atrial fibrillation ablation in patients undergoing mitral valve surgery. Semin Thorac Cardiovasc Surg. 2002;14:193-7.

13. Forlani S, De Paulis R, Guerrieri Wolf L, Greco R, Polisca P, Moscarelli M, et al. Conversion to sinus rhythm by ablation improves quality of life in patients submitted to mitral valve surgery. Ann Thorac Surg. 2006;81:863-7.

14. Ngaage DL, Schaff HV, Mullany CJ, Barnes S, Dearani JA, Daly RC, et al. Influence of preoperative atrial fibrillation on late results of mitral repair: is concomitant ablation justified? Ann Thorac Surg. 2007;84:434-42.

15. Fukunaga S, Hori H, Ueda T, Takagi K, Tayama E, Aoyagi S. Effect of surgery for atrial fibrillation associated with mitral valve disease. Ann Thorac Surg. 2008;86: 1212-7.

16. Itoh A, Kobayashi J, Bando K, Niwaya K, Tagusari O, Nakajima H, et al. The impact of mitral valve surgery combined with maze procedure. Eur J Cardiothorac Surg. 2006;29:1030-5. 
17. Kim HK, Kim YJ, Kim KI, Jo SH, Kim KB, Ahn H, et al. Impact of the maze operation combined with left-sided valve surgery on the change in tricuspid regurgitation over time. Circulation. 2005;112(9 Suppl):I14-9.

18. Stulak JM, Schaff HV, Dearani JA, Orszulak TA, Daly RC, Sundt TM 3rd. Restoration of sinus rhythm by the Maze procedure halts progression of tricuspid regurgitation after mitral surgery. Ann Thorac Surg. 2008;86:40-5.

19. Louagi Y, Buche M, Eucher P, Schoevaerdts JC, Gerard M, Jamart J, et al. Improved patient survival with concomitant Cox Maze III procedure compared with heart surgery alone. Ann Thorac Surg. 2009;87:440-6.

20. Lewis T, Drury AN, Iliescu CC. Further observations upon the state of rapid re-excitation of the auricles. Heart. 1921;8:311-40.

21. Garrey WE. Auricular fibrillation. Physiol Rev. 1924;4:215-50.

22. Allessie MA, Bonke FI, Schopman FJ. Circus movement in rabbit atrial muscle as a mechanism of tachycardia. III. The "leading circle" concept: a new model of circus movement in cardiac tissue without the involvement of an anatomical obstacle. Circ Res. 1977;41:9-18.

23. Allessie MA, Lammers WJ, Bonke FI, Hollen J. Experimental evaluation of Moe's multiple wavelet hypothesis of atrial fibrillation. In: Zipes DP, Jalife J, eds. Cardiac electrophysiology and arrhythmias. Orlando (FL): Grune \& Stratton; 1985. p. 265-75.

24. Haïssaguerre M, Jaïs P, Shah DC, Takahashi A, Hocini M, Quiniou G, et al. Spontaneous initiation of atrial fibrillation by ectopic beats originating in the pulmonary veins. N Engl J Med. 1998;339:659-66.

25. Lee SH, Tai CT, Hsieh MH, Tsao HM, Lin JY, Chang SL, et al. Predictors of nonpulmonary vein ectopic beats initiating paroxysmal atrial fibrillation: implication for catheter ablation. J Am Coll Cardiol. 2005;46:1054-9.

26. European Heart Rhythm Association (EHRA); European Cardiac Arrhythmia Society (ECAS); American College of Cardiology (ACC); American Heart Association (AHA); Society of Thoracic Surgeons (STS), Calkins H, et al. HRS/EHRA/ ECAS Expert consensus statement on catheter and surgical ablation of atrial fibrillation: recommendations for personnel, policy, procedures and follow-up. A report of the Heart Rhythm Society (HRS) Task Force on catheter and surgical ablation of atrial fibrillation. Heart Rhythm. 2007;4:816-61. Erratum in: Heart Rhythm. 2009;6:148.

27. Gillinov AM, Bakaeen F, McCarthy PM, Blackstone EH, Rajeswaran J, Pettersson G, et al. Surgery for paroxysmal atrial fibrillation in the setting of mitral valve disease: a role for pulmonary vein isolation? Ann Thorac Surg. 2006;81: 19-28.

28. Ninet J, Roques X, Seitelberger R, Deville C, Pomar JL, Robin J, et al. Surgical ablation of atrial fibrillation with off-pump, epicardial, high-intensity focused ultrasound. Results of a multicenter trial. J Thorac Cardiovasc Surg. 2005;130: 803-9.

29. Groh MA, Binns OA, Burton HG 3rd, Ely SW, Johnson AM. Ultrasonic cardiac ablation for atrial fibrillation during concomitant cardiac surgery: Long-term clinical outcomes. Ann Thorac Surg. 2007;84:1978-83.

30. Klinkenberg TJ, Ahmed S, Ten Hagen A, Wiesfeld AC, Tan ES, Zijlstra F, et al. Feasibility and outcome of epicardial pulmonary vein isolation for lone atrial fibrillation using minimal invasive surgery and high intensity focused ultrasound. Europace. 2009;11:1624-31.

31. Cox JL, Boineau JP, Schuessler RB, Kater KM, Lappas DG. Five-year experience with the maze procedure for atrial fibrillation. Ann Thorac Surg. 1994;56:814-24.

32. Lammers WJ, Schalij MJ, Kirchhof CJ, Allessie MA. Quantification of spatial inhomogeneity in conduction and initiation of reentrant atrial arrhythmias. Am J Physiol. 1990;259(4 Pt 2):H1254-63.

33. Cox JL, Boineau JP, Schuessler RB, Kater KM, Lappas DG. Surgical interruption of atrial reentry as a cure for atrial fibrillation. In: Olsson SB, Allessie MA, Campbell RW, eds. Atrial fibrillation: mechanisms and therapeutic strategies. Armonk (NY): Futura Publishing; 1994. p. 373-404.

34. Benussi S, Pappone C, Nascimbene S, Oreto G, Caldarola A, Stefano PL, et al. A simple way to treat chronic atrial fibrillation during mitral valve surgery: the epicardial radiofrequency approach. Eur J Cardiothorac Surg. 2000; 17:524-9.

35. Boineau JP, Canavan TE, Schuessler RB, Cain ME, Corr PB, Cox JL. Demonstration of a widely distributed atrial pacemaker complex in the human heart. Circulation. 1988;77:1221-37.

36. Cox JL. NASPE history: cardiac surgery for arrhythmias. Pacing Clin Electrophysiol. 2004;27:1-17.

37. Cox JL. The role of surgical intervention in the management of atrial fibrillation. Tex Heart Inst J. 2004;31:257-65.

38. Haïssaguerre M, Wright M, Hocini M, Jaïs P. The substrate maintaining persistent atrial fibrillation. Circ Arrhythm Electrophysiol. 2008;1:2-5.
39. Wolf RK, Schneeberger EW, Osterday R, Miller D, Merrill W, Flege JB Jr, et al Video-assisted bilateral pulmonary vein isolation and left atrial appendage exclusion for atrial fibrillation. J Thorac Cardiovasc Surg. 2005;130:797-802.

40. Melo J, Adragão P, Neves J, Ferreira MM, Pinto MM, Rebocho MJ, et al. Surgery for atrial fibrillation using radiofrequency catheter ablation: assessment of results at one year. Eur J Cardiothorac Surg. 1999;15:851-5.

41. Knaut M, Spitzer SG, Karolyi L, Ebert HH, Richter P, Tugtekin SM, et al. Intraoperative microwave ablation for curative treatment of atrial fibrillation in open heart surgery-the MICRO-STAF and MICRO-PASS pilot trial. MICROwave Application in Surgical Treatment of Atrial Fibrillation. MICROwave Application for the Treatment of Atrial Fibrillation in Bypass-Surgery. Thorac Cardiovasc Surg. 1999;47(Suppl. 3):379-84.

42. Dörschler K, Müller G. The role of laser in cardiac surgery. Thorac Cardiovasc Surg. 1999;47(Suppl. 3):385-7.

43. Pruitt JC, Lazzara RR, Dworkin GH, Badhwar V, Kuma C, Ebra G. Totally endoscopic ablation of lone atrial fibrillation: initial clinical experience. Ann Thorac Surg. 2006;81:1325-30.

44. Gammie JS, Didolkar P, Krowsoski LS, Santos MJ, Toran AJ, Young CA, et al. Intermediate-term outcomes of surgical atrial fibrillation correction with the CryoMaze procedure. Ann Thorac Surg. 2009;87:1452-9.

45. Salenger R, Lahey SJ, Saltman AE. The completely endoscopic treatment of atrial fibrillation: report on the first 14 patients with early results. Heart Surg Forum. 2004:7:E555-8.

46. Barnett SD, Ad N. Surgical ablation as treatment for the elimination of atrial fibrillation: a meta-analysis. J Thorac Cardiovasc Surg. 2006;131:1029-35.

47. Rostock T, Steven D, Hoffmann B, Servatius H, Drewitz I, Sydodw K, et al. Chronic atrial fibrillation is a biatrial arrhythmia: data from catheter ablation of chronic atrial fibrillation aiming arrhythmia termination using a sequential ablation approach. Circ Arrhythm Electrophysiol. 2008;1:324-6.

48. Gillinov AM. Choice of surgical lesion set: answers from the data. Ann Thorac Surg. 2007;84:1786-92.

49. The Wolf MiniMaze: the official site [Internet]. Cincinnati:Wolf RK; c2004-09 [updated $2010 \mathrm{Feb}$ 0; cited March 22, 2010]. Available at: http://www. wolfminimaze.com.

50. Kiser AC, Wimmer-Greinecker G, Chitwood WR. Totally extracardiac Maze procedure performed on the beating heart. Ann Thor Surg. 2007;84:1783-5.

51. Edgerton JR, Jackman WM, Mack MJ. A new epicardial lesion set for minimal access left atrial maze: the Dallas lesion set. Ann Thorac Surg. 2009;88:1655-7.

52. Cox JL. The surgical treatment of atrial fibrillation. IV. Surgical technique. J Thorac Cardiovasc Surg. 1991;101:584-92.

53. Cox JL, Boineau JP, Schuessler RB, Jaquiss RD, Lappas DG. Modification of the maze procedure for atrial flutter and atrial fibrillation. I. Rationale and surgical results. J Thorac Cardiovasc Surg. 1995;110:473-84.

54. Cox JL, Jaquiss RD, Schuessler RB, Boineau JP. Modification of the maze procedure for atrial flutter and atrial fibrillation. II. Surgical technique of the maze III procedure. J Thorac Cardiovasc Surg. 1995; 110:485-95.

55. Cox JL, Canavan TE, Schuessler RB, Cain ME, Lindsay BD, Stone C, et al. The surgical treatment of atrial fibrillation. II. Intraoperative electrophysiologic mapping and description of the electrophysiologic basis of atrial flutter and atrial fibrillation. J Thorac Cardiovasc Surg. 1991;101:406-26.

56. Cox JL, Ad N. The importance of cryoablation of the coronary sinus during the Maze procedure. Semin Thorac Cardiovasc Surg. 2000;12:20-4.

57. Katritsis D, Ioannidis JP, Giazitzoglou E, Korovesis S, Anagnostopoulos CE Camm AJ. Conduction delay within the coronary sinus in humans: implications for atrial arrhythmias. J Cardiovasc Electrophysiol. 2002;13:859-62.

58. Oral H, Ozaydin M, Chugh A, Scharf C, Tada H, Hall B, et al. Role of the coronary sinus in maintenance of atrial fibrillation. J Cardiovasc Electrophysiol. 2003;14 1329-36.

59. Olgin JE, Jayachandran JV, Engelstein E, Groh W, Zipes DP. Atrial macroreentry involving the myocardium of the coronary sinus: a unique mechanism for atypical flutter. J Cardiovasc Electrophysiol. 1998;9:1094-9.

60. Ndrepera G, Zrenner B, Schneider MA, Schreieck J, Karch MR, Schömig A, et al. Dissociation between coronary sinus and left atrial conduction in patients with atrial fibrillation and flutter. J Cardiovasc Electrophysiol. 2001;12:623-8.

61. Katritsis DG, Giazitzoglou E, Korovesis S, Karvouni E, Anagnostopoulos CE, Camm AJ. Conduction patterns in the cardiac veins: electrophysiologic characteristics of the connections between left atrial and coronary sinus musculature. J Interv Cardiac Electrophysiol. 2004;10:1-8.

62. Canavan TE, Schuessler RB, Boineau JP, Corr PB, Cain ME, Cox JL. Computerized global electrophysiological mapping of the atrium in patients with WolffParkinson-White syndrome. Ann Thorac Surg. 1988;46:223-31. 
63. Cox JL, Schuessler RB, Lappas DG, Boineau JP. An $8 \frac{1}{2} 2$ year clinical experience with surgery for atrial fibrillation. Ann Surg. 1996;224:267-75.

64. Ziegler PD, Koehler JL, Mehra R. Comparison of continuous versus intermittent monitoring of atrial arrhythmias. Heart Rhythm. 2006;3:1445-52.

65. Ad N, Henry L, Hunt S, Barnett S, Stone L. The Cox-Maze III procedure success rate: comparison by electrocardiogram, 24-hour holter monitoring and long-term monitoring. Ann Thorac Surg. 2009;88:101-5.

66. Prasad SM, Maniar HS, Camillo CJ, Schuessler RB, Boineau JP, Sundt TM 3rd, et al. The Cox maze III procedure for atrial fibrillation: long-term efficacy in patients undergoing lone versus concomitant procedures. J Thorac Cardiovasc Surg. 2003; $126: 1822-8$.

67. Cox JL, Schuessler.B D'Agostino HJ Jr, Stone CM, Chang BC, Cain ME, et al. The surgical treatment of atrial fibrillation. III. Development of a definitive surgical procedure. J Thorac Cardiovasc Surg. 1991;101:569-83.

68. Cappato R, Calkins H, Chen SA, Davies W, Iesaka Y, Kalman J, et al. Up-dated worldwide survey on the methods, efficacy, and safety of catheter ablation for human atrial fibrillation. Circ Arrhythm Electrophysiol. 2010;3:32-8.
69. Cox JL. The central controversy surrounding the interventional-surgical treatment of atrial fibrillation. J Thorac Cardiovasc Surg. 2005;129:1-4.

70. Peters DC, Wylie JV, Hauser TH, Kissinger KV, Botnar RM, Essebag V, et al. Detection of pulmonary vein and left atrial scar after catheter ablation with three-dimensional navigator-gated delayed enhancement MR imaging: initial experience. Radiology. 2007;243:690-5.

71. Wylie JV, Peters DC, Essebag V, Manning WJ, Josephson ME, Hauser TH. Left atrial function and scar after catheter ablation of atrial fibrillation. Heart Rhythm. 2008;5:656-62.

72. Sick PB, Schuler G, Hauptmann KE, Grube E, Yakubov S, Turi ZG, et al. Initial worldwide experience with the WATCHMAN left atrial appendage system for stroke prevention in atrial fibrillation. J Am Coll Cardiol. 2007;49: 1490-5.

73. Holmes DR, Reddy VY, Turi ZG, Doshi SK, Sievert H, Buchbinder M, et al. Percutaneous closure of the left atrial appendage versus warfarin therapy for prevention of stroke in patients with atrial fibrillation: a randomised non-inferiority trial. Lancet. 2009;15:374534-42. Erratum in: Lancet.2009;374:1596. 